\title{
Knowledge, Attitude, and Practice of Preventing the Occurrence of Work-Related Musculoskeletal Disorders among Doctors in University of Port Harcourt Teaching Hospital
}

\author{
Benson Chukwunweike Ephraim-Emmanuel ${ }^{1}$, Ronami Ogbomade ${ }^{2}$, \\ Innocent Ugwoke ${ }^{3}$, Blackman Nabai Idumesaro²
}

${ }^{1}$ Department of Preventive and Social Medicine, University of Port Harcourt, PortHarcourt, Nigeria, ${ }^{2}$ Department of Science Foundation, Bayelsa State College of Health Technology, Otuogidi, Ogbia, Nigeria, ${ }^{3}$ Department of Dental Health Science, Bayelsa State College of Health Technology, Otuogidi, Ogbia, Nigeria

Address for correspondence: Benson Chukwunweike Ephraim-Emmanuel, Department of Preventive and Social Medicine, University of Port Harcourt, Port Harcourt, Nigeria. Tel.: +234-806-003-8135.

E-mail: benchike2002@yahoo.com

\section{Abstract}

Background: Musculoskeletal disorders affecting medical personnel should never be treated lightly. It has, thus, becomenecessarytostrictlyinfuseergonomics in medical practice totackletheoccurrence of musculoskeletal system disorders. This would ensure better productivity among the medical personnel. This research was conducted to determine the knowledge, attitude, and practice of the prevention of workrelated musculoskeletal disorders (WRMSDs) among doctors working at the University of Port Harcourt Teaching Hospital (UPTH). Materials and Methods: A descriptive, cross-sectional study design was employed in carrying out this study among doctors working at the UPTH. Multistage sampling was utilized in selecting a sample population of 223 doctors for this study. Data collection was done using a semi-structured selfadministered questionnaire. Ethical approval to conduct this study was obtained from the University of PortHarcourtResearch Ethics Committee. Consent, confidentiality, privacy, and beneficence were ensured in this study. For the test of associations, statistical significance was set at 0.05 . Results: Majority of the respondents had good knowledge and attitude toward musculoskeletal disorders' prevention at work. The practice of ergonomic principles was, however, not satisfactory. The occurrence of WRMSDs among study respondents was significantly associated with the knowledge and practice of ergonomic principles required to prevent the occurrence of these disorders. Conclusion: Despite the significant proportion of doctors in this study having good knowledge and attitude toward prevention of musculoskeletal system disorders at work, only a few of these doctors satisfactorily practiced the necessary preventive measures necessary to prevent these disorders. This inadvertently resulted in the high prevalence of these disorders found in this study. It is recommended that health personnel should be re-oriented to be more involved in the actual application of ergonomics while working no matter the compulsion or desire to get work done.

\section{Keywords: Musculoskeletal disorders, workplace, knowledge, attitude, practice, prevention, ergonomic} principles

\section{Introduction}

Health-care workers are constantly exposed to workplace hazards which could be biological, chemical, physical, social, or mechanical in nature. These hazards and continuous exposure to them are known to bring about deleterious effects on

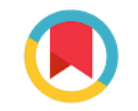

Check for updates

JMR

How to cite this article: Ephraim-Emmanuel BC, Ogbomade R, Ugwoke I, Idumesaro BN. Knowledge, Attitude, and Practice of Preventing the Occurrence of Work-Related Musculoskeletal Disorders among Doctors in University of Port Harcourt Teaching Hospital. 2019;3(2):e000161.

DOI: 10.32892/jmri.161.

Publication history: Received: 31-12-2018 Accepted: 15-02-2019 Published: 17-02-2019

Editor: Dr. Varshil Mehta

Copyright:

Ephraim-Emmanuel BC, Ogbomade R, Ugwoke I, Idumesaro $B N$. This is an open access article distributed under the terms of the Creative Commons Attribution License CC-BY 4.0. which permits unrestricted use, distribution, and reproduction in any medium, provided the original author and source are credited.

Funding: NIL

Conflict of Interest: NIL Medkrux 


\section{Ephraim-Emmanuel, et al.: KAP preventing Work-related musculoskeletal disorders}

the well-being of those exposed, who in this case, are doctors providing health care and include physicians, dentists, hematologists, pathologists, radiologists, and surgeons. ${ }^{[1-4]}$ During treatment sessions, doctors in differentspecialties of medicine are exposed to hazards related to a strained posture which exerts a destabilizing effect on the osteoarticular system of the body, thus invariably having negative effects on the affected muscles and joints and resulting in musculoskeletal system disorders. These disorders have the propensity of adversely affecting the health and practice of those affected. ${ }^{[5-9]}$

Toprevent the occurrence of these disorders, it is necessary that ergonomic principles are infused in all aspects of medical practice. This would ensure better productivity and job satisfaction among the personnel. ${ }^{[9-11]}$ However, for effective application of the principle of ergonomics to prevent these disorders, doctors must first have good knowledge of the risk factors implicated in theiroccurrence and how to apply the principles. Ergonomics is an applied science involving processes, procedures, and product design which ensures work efficiency and the health and safety of the worker. It involves applying theory, principles, and design in an occupational environment to ensure optimal human well-being and overall system performance. ${ }^{[12]}$ Required goals for the application of ergonomics in medical practice include reduced pain and morbidities associated with medical practice, decreased stress while working, improved musculoskeletal health and vigor, increased comfort at work, increased productivity while working, career span improvement as well as improved quality of life. ${ }^{[3]}$

Practices encouraging the prevention of the occurrence of these disorders include ensuring that the working chair/stool be fashioned to support the worker in neutral posture by being fully adjustable and having a broad base and a little forward tilt in order for easy achievability of optimal access, clear visibility, and comfort while working. Others include good use of the backrest to ensure optimum lumbar support of the body trunk, avoiding flexed back positions, alternating working postures to allow for muscle recovery as well as exercising including head rotations (in the 4 different planes of movement). More of these practices include looking away from work area and focusing eyes at the ceiling for some seconds, shoulder shrugging, clasping of fingers behind the occipital region of the head, interlacing fingers and turning the palms outwards etc. The use of an extra pair of hands while working which is provided by technical assistants, ensuring ergonomic considerations involving equipment/ instrument design during their purchase as well as working in a well-illuminated environment with the temperature well-adjusted to promote adequate muscular blood circulation are all effective practices that could encourage the prevention of these disorders. ${ }^{[3,10-14]}$

Knowledge as well as the actual practice of necessary principles required for the prevention of work-related musculoskeletal disorders (WRMSDs) remains an issue to be addressed considering reports from a number of studies. In a study among dental students and dental practitioners, only $21.4 \%$ of respondents had good knowledge of ergonomics application to prevent these disorders with an attendant report that only $10.7 \%$ of the study respondents had good practice scores of ergonomics in preventing disorders of the musculoskeletal system. ${ }^{[15]}$ Health workers who had poor knowledge of applying ergonomic principles at work and were thus unable to avoid factors associated with the development of adverse health conditions (including disorders of the musculoskeletal system) have also been reported. ${ }^{[16]}$ In another study, $50.64 \%$ of respondents were reported to have no knowledge of applying ergonomics in preventing musculoskeletal system disorders. ${ }^{[17]}$ However, on the contrary, in another study, authors reported a satisfactory knowledge and attitude toward ergonomics among students in preventing musculoskeletal system disorders. This is evidenced by $52 \%$ and $75 \%$ overall mean knowledge and attitude scores obtained, respectively, in their study. ${ }^{[18]}$ Furthermore, in a Pakistani study on the ergonomic hazards to dental surgeons, it was reported that all the respondents supported the importance of maintaining ideal working postures, thus showing a high proportion with a positive attitude. ${ }^{[19]}$ This notwithstanding, only $8.3 \%$ of the respondents always applied ergonomics while working while $26.4 \%$ applied it most of the time. However, $64.5 \%$ of them seldom applied the principle of ergonomics while working with a resultant majority coming down with these disorders. ${ }^{[19]}$ Karibasappa et al. ${ }^{[20]}$ also reported that $75-87.23 \%$ of respondents had good attitude toward the application of ergonomics in their medical practice. However, only $34-49 \%$ of the respondents in their study practiced the application of ergonomics by adopting working postures that were adequate to prevent the occurrence of these disorders. 


\section{Ephraim-Emmanuel, et al.: KAP preventing Work-related musculoskeletal disorders}

Having identified this problem and seeing its ability to reduce work efficiency and general well-being of doctors coupled with the absence of published data to confirm these reports among doctors working at the University of Port-Harcourt Teaching Hospital (UPTH), Rivers State, Nigeria; it has, thus, become necessary to conduct this research as it would provide lacking epidemiological data on the need to ensure the application of ergonomics in clinical practice due to the vulnerabilities that the practice exposes its practitioners to. It would also provide a stimulating effect capable of spurring required agencies of government into action that ensures the optimal maintenance of the health and efficiency of her medical personnel. It is, thus, necessary to conduct this study to determine the knowledge, attitude, and practice of WRMSDs among doctors working at theUPTH.

\section{Materials and Methods}

The descriptive, cross-sectional study design was used in carrying out this research study. This study was conducted at the UPTH which is located along the East-West road at Choba, Obi-Akpor Local Government Area of Port Harcourt metropolis. Alongside the provision of clinical services round the clock, UPTH also provides clinical training and education to health-care professionals. Atypical day at work at the UPTH involves delivering medical care to both in- and out-patients and provides clinical training and education to health-care professionals. ${ }^{[21,22]}$

Using Fisher's formula: $n=Z \alpha 2 p q / d 2$, the minimum sample size was calculated. ${ }^{[23]}$ Where: $n=$ minimum sample size required, $Z \alpha=$ value corresponding to the confidence level of $95 \%$ which is 1.96 . $p=$ percentage or proportion of the attribute of interest from the previous study. In this case musculoskeletal disorder; $q=100-p, d=$ errormargin (5\%). A proportion of $84.4 \%$ was gotten from a previous study, ${ }^{[24]}$ thus: $n=1.962 \times(84.4 * 15.6) / 52=$ $(3.8416 \times 1316.64) / 25=5058.00 / 25=202.223$ respondents were finally selected considering a $10 \%$ non-response rate. A multistage sampling was conducted. The first stage was a stratified sampling of the population into the different specialties of medical practice presently providing health-care services at the UPTH. The second stage was a stratified sampling of the doctors into their different working cadres which included consultants, senior registrars, and registrars. The third stage involved the selection of respondents based on availability and willingness to participate in the study considering the increased workload on the study respondents as a result of the industrial action organized by the Joint Health Sector Unions during the course of carrying out this study. Data collection was done over a period of 14 days with the help of a research assistant who was educated on the objectives of the research and on how to ensure proper data collection.

A semi-structured self-administered questionnaire wasusedasthestudyinstrument. Thequestionnaire was adapted from pre-existing templates..$^{[11,25-27]}$ The questionnaire probed the presence or absence of musculoskeletal disorders. The knowledge of the respondents regarding ergonomics application to prevent disorders of the musculoskeletal system while at work was also probed. Yes and no options were provided for 15 questions asked in this section. 12 positively worded and 3 questions having negative responses were asked to elicit their knowledge of how to prevent disorders of the musculoskeletal system. Examples of questions having positive responses asked included if taking adequate breaks between work procedures prevented disorders of the musculoskeletal system, if keeping the shoulders relaxed could prevent disorders of the musculoskeletal system, if forceful hand exertions have the propensity result in disorders of the musculoskeletal system, if frequent lifting of heavy equipment at work could contribute to disorders of the musculoskeletal system, if stretching exercises could be useful in preventing disorders of the musculoskeletal system from occurring amongst others. Questions having negative responses asked included if rest while working could contribute to the occurrence of musculoskeletal system disorders, if grasping small instruments for long periods could prevent disorders of the musculoskeletal system etc. Correctly answering between 11 and 15 questions was regarded as having good knowledge. Correctly answering between 6 and 10 questions was regarded as having fair knowledge, and correctly answering between 1 and 5 questions was regarded as having poor knowledge.

The next section sought their attitude toward the application of ergonomics in preventing the occurrence of disorders of the musculoskeletal system. Yes and no options were provided for 10 questions asked in this section. 6 negatively worded and 4 questions having positive responses were asked to elicit their attitude toward ergonomics

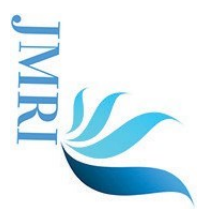




\section{Ephraim-Emmanuel, et al.: KAP preventing Work-related musculoskeletal disorders}

application in preventing disorders of the musculoskeletal system. Questions having negative responses included if it was preferable to bend the head forward instead of adjusting the workspace in a bid to view the workspace better, if they could not do without bending their backs while working, and if taking breaks while working was a waste of time amongst others. Questions having positive responses asked included if keeping the back supported while working was always a considered option, if applying ergonomic principles at work to avoid disorders of the musculoskeletal system was an achievable task among others. Correctly answering between 6 and 10 questions was regarded as having a good attitude, and correctly answering between 1 and 5 questions was regarded as having a poor attitude.

Finally, ergonomic practices applied at the workplace were also elicited. This was a multiple choice question, in which respondents were allowed to choose all options that applied to them. 15 options were provided and they included gentle hand movements, changing positions while working, placing feet flat on the floor while working, taking intermittent breaks while working, keeping the back supported while sitting as well as working with assistance when necessary. Others included keeping the shoulders relaxed while working, keeping the neck tilted only within safe limits, ensuring and/or advocating ergonomically considered shift duties, adjustment of workspace for better viewing and engaging in physical activity while working.

The last batch of options included consciously positioning body within safe ergonomic limits while working, consideration of ergonomic principles when purchasing work tools, materials and equipment; stopping work activity for a while when discomfort arose and ensuring orderliness of work instruments while working

Application of 11-15 ergonomic practices was regarded as having good practice. Application of 6-10ergonomic practiceswas regardedashavingfair practice and application of 1-5 ergonomic practices was regarded as having poor practice. How often the selected measures were applied was also enquired. The knowledge of the prevention of WRMSDs, attitude toward the application of ergonomic principles in preventing WRMSDs and the ergonomic practices applied to prevent WRMSDs from occurring; were statistically tested for association with the occurrence of WRMSDs using the chi- squared analytical test. Statistical significance was set at the 0.05 level of significance.

\section{Results}

In this study, as shown in Table 1, majority of the respondents were male, $133(59.6 \%)$, and $90(40.4 \%)$ were female. Majority of the respondents, $149(71.0 \%)$, were within the age group of 30-39 years. Majority of the respondents, $150(67.3 \%)$, were married and $73(32.7 \%)$

Table 1: Demographic characteristics of the study respondents

\begin{tabular}{|l|c|}
\hline Variable & Frequency (n=223) (\%) \\
\hline Age (years) & $14(6.7)$ \\
\hline $20-29$ & $149(71.0)$ \\
\hline $30-39$ & $39(18.6)$ \\
\hline $40-49$ & $6(2.9)$ \\
\hline $50-59$ & $2(1.0)$ \\
\hline $60-69$ & \\
\hline Gender & $133(59.6)$ \\
\hline Male & $90(40.4)$ \\
\hline Female & \\
\hline Marital status & $150(67.3)$ \\
\hline Single & $73(32.7)$ \\
\hline Married & \\
\hline Cadre & $150(67.3)$ \\
\hline Registrar & $45(20.2)$ \\
\hline Senior registrar & $28(12.5)$ \\
\hline Consultant & \\
\hline Yearsofpractice(years) & $111(51.4)$ \\
\hline $1-5$ & $66(30.6)$ \\
\hline $6-10$ & $20(9.2)$ \\
\hline $11-15$ & $19(8.8)$ \\
\hline$>20$ & $132(59.2)$ \\
\hline Specialty & $91(40.8)$ \\
\hline Surgeons & \\
\hline Physicians & \\
\hline & \\
\hline
\end{tabular}

Table 2: Prevalence of musculoskeletal system disorders

Experience of MSD symptom Frequency $(n=223)(\%)$

\begin{tabular}{|l|c|}
\hline Yes & $202(90.6)$ \\
\hline No & $21(9.4)$ \\
\hline
\end{tabular}




\section{Ephraim-Emmanuel, et al.: KAP preventing Work-related musculoskeletal disorders}

were single. According to cadre, majority of the respondents were registrars, 150 (67.3\%), $45(20.2 \%)$ were senior registrars, and $28(12.5 \%)$ were consultants. Majority of the study respondents $(111,51.4 \%)$ had practiced for $1-5$ years. Majority of the respondents were surgeons, 132(59.2\%), and the other physicians, 91 (40.8\%).

According to Table 2, majority of the respondents, $202(90.6 \%)$, had experienced symptoms of work-

Table 3: Knowledge of work-related musculoskeletal system disorders' prevention

\begin{tabular}{|l|l|}
\hline Level of knowledge & Frequency ( $\boldsymbol{n = 2 2 3 )}$ (\%) \\
\hline $\begin{array}{l}\text { Good knowledge (selected } \\
11-15 \text { correct options) }\end{array}$ & $215(96.4)$ \\
\hline $\begin{array}{l}\text { Fair knowledge (selected } \\
6-10 \text { correct options) }\end{array}$ & $8(3.6)$ \\
\hline $\begin{array}{l}\text { Poor knowledge (selected 1- } \\
5 \text { correct options) }\end{array}$ & $0(0.0)$ \\
\hline
\end{tabular}

Table 4: Attitude toward work-related musculoskeletal disorder prevention

\begin{tabular}{|l|c|}
\hline Attitude & Frequency ( $\boldsymbol{n}=223)(\%)$ \\
\hline $\begin{array}{l}\text { Good attitude (selected } \\
6-10 \text { correct options) }\end{array}$ & $216(96.9)$ \\
\hline $\begin{array}{l}\text { Poor attitude (selected 1-5 } \\
\text { correct options) }\end{array}$ & $7(3.1)$ \\
\hline
\end{tabular}

related musculoskeletal system disordersinthe past 12 months. This, thus, gives aWRMSDs prevalence of $90.6 \%$ among the study respondents.

Table 3 shows that majority of the respondents had good knowledge $(215,96.4 \%)$ as they were able to correctly respond to eleven or more of 15 questions asked to assess their knowledge. 8 (3.6\%) of the respondents, however, had fair knowledge regarding WRMSD prevention. No respondent had poor knowledge of the prevention of work-related musculoskeletal system disorders.

With reference to the 6 negatively worded and 4 questions having positive responses asked to elicit respondents' attitude toward WRMSD prevention, Table 4 shows that majority of the respondents $216(96.9 \%)$ had a good attitude toward WRMSDs' prevention. $7(3.1 \%)$ of the respondents, however, had a poor attitude toward WRMSDs' prevention. With reference to the ergonomic principles for which the respondents were assessed for practice to prevent work-related musculoskeletal system disorders, Table 5 shows that the most practiced principle was the changing of positions while working 196 (87.9\%) followed by keeping the back supported when sitting $173(77.6 \%)$, keeping the shoulders relaxedwhileworking $173(77.6 \%)$, taking intermittent breaks while working 172 (77.1\%), and ensuring gentle hand movements while working $155(69.5 \%)$ among others. Keeping the neck tilted

Table 5: Ergonomic principles practiced by respondents

\begin{tabular}{|l|c|}
\hline Ergonomic principles & Frequency \\
\hline Changing positions while working & 196 \\
\hline Keeping back supported while sitting & 173 \\
\hline Keeping shoulders relaxed while working & 173 \\
\hline Taking intermittent breaks while working & 155 \\
\hline Ensuring gentle hand movements & 121 \\
\hline Engaging in physical activity while working, e.g., stretching etc. & 120 \\
\hline Ensuring and/or advocating for ergonomically considered shift duties & 113 \\
\hline Adjusting the workspace for better operator-patient positioning & 112 \\
\hline Working with assistance when necessary & 102 \\
\hline Stopping work activity for a while when discomfort arises & 57 \\
\hline Ensuring orderliness of work instruments while working & 53 \\
\hline Consciously positioning the body within safe ergonomic limits while working & 51 \\
\hline Placing feet flat on the floor when working & 50 \\
\hline Keeping neck tilted only within safe limits & 29 \\
\hline $\begin{array}{l}\text { Consideration of ergonomic principles when purchasing work materials, tools and/or } \\
\text { equipment }\end{array}$ & \\
\hline
\end{tabular}

*There were multiple responses 


\section{Ephraim-Emmanuel, et al.: KAP preventing Work-related musculoskeletal disorders}

as well as consideration of ergonomic principles when purchasing work materials, tools and/or equipment were, however, the least practiced ergonomic principles.

With reference to the 15 ergonomic principles enquired about from which respondents selected the practices thatthey applied when atwork, Table 6 shows that majority of the study respondents fairly practiced these principles $145(65.0 \%) .31(13.9 \%)$ had a good level of practice of these ergonomic principles; however, $47(21.1 \%)$ respondents poorly practiced these ergonomic principles. As shown in Table 7, it was also found that these principles were mostly only practiced sometimes $153(68.6 \%)$ by the study respondents. $51(22.9 \%)$ respondents rarely practiced them, whereas only $18(8.1 \%)$ respondents always practiced these ergonomic principles while at work. $1(0.4 \%)$ respondent, however, never practiced these ergonomic principles.

With reference to work practices precipitating work-related musculoskeletal system disorders among the study respondents, Table 8 shows that working for prolonged periods without rest or breaks $135(60.5 \%)$ was the mostoccurring practice reported to precipitate symptoms of work-related disorders of the musculoskeletal system. This was followed by standing for long periods while working $120(53.8 \%)$ as well as sitting for long periods while working $93(41.7 \%)$.

Table 9 shows a statistically significant association between knowledge and practice of WRMSDs' prevention and the presence of WRMSDs. The table shows that respondents have a good knowledge of work-related musculoskeletal system disorders' prevention presented with more cases of symptoms of musculoskeletal system disorders than those having fair knowledge of how to prevent work-related musculoskeletal system disorders $(P=0.006)$. The table also shows that respondents with a fair or poor level of practice of ergonomic principles that prevent the occurrence of workrelated disorders of the musculoskeletal system presented with morecases ofsymptoms ofdisorders of the musculoskeletal system than those with a good level of practice of ergonomic principles that prevent the occurrence of work-related disorders of the musculoskeletal system $(P=0.000)$.

\section{Discussion}

For effective application of ergonomic principles in preventing work-related musculoskeletal system
Table 6: Level of ergonomic principles practiced by the respondents

\begin{tabular}{|l|c|}
\hline Level of practice & Frequency $(\boldsymbol{n}=223)(\%)$ \\
\hline $\begin{array}{l}\text { Good practice (applied } \\
11-15 \text { ergonomic practices) }\end{array}$ & $31(13.9)$ \\
\hline $\begin{array}{l}\text { Fairpractice(applied6-10 } \\
\text { ergonomic practices) }\end{array}$ & $145(65.0)$ \\
\hline $\begin{array}{l}\text { Poor practice (applied 1-5 } \\
\text { ergonomic practices) }\end{array}$ & $47(21.1)$ \\
\hline
\end{tabular}

Table 7: Frequency of practice of the ergonomic principles

\begin{tabular}{|l|c|c|}
\hline Frequency of practice & \multicolumn{2}{|c|}{ Frequency $(\boldsymbol{n}=\mathbf{2 2 3})(\%)$} \\
\hline Always & 18 & 8.1 \\
\hline Sometimes & 153 & 68.6 \\
\hline Rarely & 51 & 22.9 \\
\hline Never & 1 & 0.4 \\
\hline
\end{tabular}

Table 8: Work practices precipitating work-related musculoskeletal system disorders

\begin{tabular}{|l|c|}
\hline Work practices & Frequency \\
\hline Working for long periods without rest & 135 \\
\hline Standing for long periods whileworking & 120 \\
\hline Sitting for long periods while working & 93 \\
\hline $\begin{array}{l}\text { Occurrence of repetitive hand } \\
\text { movements while working }\end{array}$ & 64 \\
\hline $\begin{array}{l}\text { Working while sitting on an unadjustable } \\
\text { chair }\end{array}$ & 47 \\
\hline Bending the neck/back to view work area & 44 \\
\hline Working withachairhaving no backrest & 34 \\
\hline $\begin{array}{l}\text { Maintaining fixed neck postures while } \\
\text { working }\end{array}$ & 31 \\
\hline $\begin{array}{l}\text { Grasping workinstruments for prolonged } \\
\text { periods }\end{array}$ & 20 \\
\hline Lifting heavy workplace equipment & 14 \\
\hline Carrying patient samples & 12 \\
\hline Useofvibrating tools/equipmentatwork & 6 \\
\hline
\end{tabular}

*There were multiple responses

disorders, it is important that health personnel including doctors should know what these principles are about and how they can be achieved. On this premise, an assessment of knowledge of musculoskeletal system disorders' prevention at work was carried out in this study. This assessment showed that majority of the respondents had good knowledge 217 (96.4\%) of musculoskeletal 


\section{Ephraim-Emmanuel, et al.: KAP preventing Work-related musculoskeletal disorders}

Table 9: Association between knowledge, attitude, and practice of the prevention of WRMSDs and the occurrence of WRMSDs

\begin{tabular}{|c|c|c|c|c|c|}
\hline \multirow[t]{2}{*}{ Variable } & \multicolumn{3}{|c|}{ Work-related musculoskeletal disorder } & \multirow[t]{2}{*}{ df } & \multirow[t]{2}{*}{$X^{2}$ (P-value) } \\
\hline & Present & Absent & Total & & \\
\hline Knowledge & & & & 1 & $7.672(0.006)^{*}$ \\
\hline Good (11-15) & $197(91.6)$ & $18(8.4)$ & $215(96.4)$ & & \\
\hline Fair $(6-10)$ & $5(62.5)$ & $3(37.5)$ & $8(3.6)$ & & \\
\hline Total & $202(90.6)$ & $21(9.4)$ & $223(100.0)$ & & \\
\hline Attitude & & & & 1 & $0.201(0.654)$ \\
\hline Good (6-10) & $196(90.7)$ & $20(9.3)$ & 216 (96.9) & & \\
\hline Poor (1-5) & $6(85.7)$ & $1(14.3)$ & $7(3.1)$ & & \\
\hline Total & $202(90.6)$ & $21(9.4)$ & $223(100.0)$ & & \\
\hline Practice & & & & 1 & $16.240(0.000)^{*}$ \\
\hline Good (11-15) & $22(71.0)$ & $9(29.0)$ & $31(13.9)$ & & \\
\hline Fair/Poor (6-10/1-5) & $180(93.7)$ & $12(6.3)$ & $192(86.1)$ & & \\
\hline Total & $202(90.6)$ & $21(9.4)$ & $223(100.0)$ & & \\
\hline
\end{tabular}

*Signifies a significant association between variables. WRMSDs: Work-related musculoskeletal disorders

system disorders' prevention at work. 8(3.6\%) of the respondents, however, had fair knowledge regarding musculoskeletal system disorders' prevention at work. No respondent had poor knowledge of musculoskeletal system disorders' prevention at work. This high proportion of study respondents having good knowledge of how to prevent these work-related disorders is in line with the findings of the study by Kalghatgi et al. ${ }^{[18]}$ in which satisfactory knowledge of ergonomics among dental professionals in preventing musculoskeletal system disorders was reported. Another study also corroborates the results of this study, in which satisfactory knowledge about ergonomics was reported among dentistry students. ${ }^{[15]}$

This high proportion of knowledge among study respondents is, however, not supported by the results of previous research in which it was reported that as much as $50.64 \%$ of respondents had no knowledge of ergonomics ${ }^{[17]}$ Having such large proportions of workers having poor knowledge of ergonomics or its application has been shown by literature to be detrimental to the ability to imbibe practices that would prevent work-related musculoskeletal system disorders due to their being not able to stay away from factors that have been associated with these disorders. ${ }^{[16]}$ In relation to knowledge, it has been shown that, when years of clinical experience are combined with informal training among practicing health personnel, there tends to be better knowledge and practice of ergonomics with an attendant low musculoskeletal system disorders' prevalence among this health personnel when compared with student trainees. ${ }^{[15]}$ In this study, the attitude of the respondents toward the application of ergonomic principles to prevent work-related musculoskeletal was assessed. This assessment showed that majority of the respondents had good attitude toward musculoskeletal system disorders' prevention at work $218(96.9 \%)$. This result is also in line with the findings of Kalghatgi et al. ${ }^{[18]}$ who also reported a high attitude score of $75 \%$. This result is further supported by the results of Bushra et al..$^{[19]}$ who reported that all respondents in theirstudy accepted the importance of applying ergonomics while working. These reports coupled with the finding of this study show that there was a good acceptance of ergonomic practices while at work to prevent work-related musculoskeletal system disorders from occurring. The attitude of the respondents in this study toward the prevention of musculoskeletal system disorders was also significantly associated with the knowledge of the respondents on the prevention of these disorders $(P=0.000)$. This is also corroborated by the results of authors who reported significantly good knowledge and attitude toward the practice of ergonomics to prevent workrelated musculoskeletal system disorders. ${ }^{[20]}$ It should, however, be noted that, when knowledge and attitude are good toward preventing workrelated musculoskeletal system disorders, the 


\section{Ephraim-Emmanuel, et al.: KAP preventing Work-related musculoskeletal disorders}

actual practice of ergonomic principles must be ensured if these work-related disorders are to be prevented. ${ }^{[28]}$

In this study, only $13.9 \%$ of the respondents had a good level of practice of the required ergonomic principles needed to prevent work-related disorders of the musculoskeletal system. This finding agrees with the findings of authors who reported that only $10.7 \%$ of the study respondents had good practice scores of ergonomics in preventing disorders of the musculoskeletal system. ${ }^{[15]}$ Reports of Karibasappa et al., ${ }^{[20]}$ are, however, not in line with the findings of this studyas $34-49 \%$ of the respondents in their study practiced the application of ergonomics by adopting working postures that were adequate. This may have been due to their study setting which sampled only dentists as against doctors of different specialties sampled in this study. This finding is also not in agreement with the findings of authors who reported that $66.25 \%$ of the respondents in their study whom had knowledge of ergonomics actually applied the principles while working. ${ }^{[17]}$ This contrary report, however, may have been due to the small sample size (80) used for their study. Other authors in their study also reported a good practice score of $55 \%$ which does not agree with the findings of this study. ${ }^{[18]}$

Despite majority of respondents having good knowledge and attitude towardmusculoskeletal system disorders' prevention at work in this study, majority of respondents in this study also had a low level of practice of the required principles to prevent these disorders. Karibasappa et al., ${ }^{[20]}$ in their study reported that, despite having good knowledge and attitude toward applying ergonomics to prevent musculoskeletal diseases, the level of practice was poor, and as mentioned previously, this poor practice is capable of influencing work-related disorders of the musculoskeletal system. ${ }^{[19]}$ In this study, this is explainable in that majority of study respondents were junior cadre doctors (registrars) who apart from having less number of years of clinical practice, are also the ones assigned bulk of the work, and are usually compelled to perform the tasks within a limited timeframe. Due to these, they usually pay less attention to ergonomics application in their clinical practice. This is further buttressed by the theory that, unless and until the practice of a preventive measure is adequate, the actual prevention of the particular disorder may not be achieved even though knowledge and attitude toward preventing the disorder are adequate. ${ }^{[28,29]}$
It is important to note that these principles were only practiced sometimes by majority $(68.4 \%)$ of the study respondents and practiced always by only $8.0 \%$ of the respondents. As much as $22.7 \%$ of the respondents rarely practiced these principles, and two doctors $(0.9 \%)$ reported never practicing these necessary ergonomic principles. This further buttress the point that, when poor ergonomic practices are prevalent at the workplace, there is a tendency for work-related disorders of the musculoskeletal system to occur. The positive effects of having good knowledge and attitude in preventing work-related disorders of the musculoskeletal system from occurring can only, therefore, be achieved when the required ergonomic principles are effectively practiced. ${ }^{[28,30-32]}$

Ergonomic principles significantly shown to have good protective effects from disorders of the musculoskeletal system among our study respondents included stopping work activity for some time whenever discomfort arose, keeping the back supported while sitting at work, ensuring orderliness of work instruments while working, and placing the feet flat on the floor while working amongst others. This finding is supported by previous literature, in which these ergonomic principles and practices were reported as necessary ways to ensure that work-related musculoskeletal system disorders were prevented from occurring. ${ }^{[6,10-12]}$

It has been earlier shown that having good knowledge of how to prevent these disorders should result in having a reduction in the prevalence of the disorders. However, despite the high proportion of respondents having good knowledge of how to prevent disorders of the musculoskeletal system (96.4\%), there was still a high prevalence of disorders of the musculoskeletal system among them. This could be explainable by majority of the doctors involved in this study being registrars who are usually involved in carrying out a number of duties assigned to them by their senior registrars and consultants. The high prevalence of thedisorderinthisstudycouldalso beasa result of the attitude of the respondents toward the practice of ergonomic principles to prevent disorders of the musculoskeletal system from occurring as well as the actual practice of these ergonomic principles by the registrars in this study who form a majority and who may not have had as much practice clinical experience as to effectively applying the principles of ergonomics in their practice. ${ }^{[14,16,19]}$ 


\section{Ephraim-Emmanuel, et al.: KAP preventing Work-related musculoskeletal disorders}

Respondents with a fair or poor level of practice of musculoskeletal system disorders' prevention at work presented with more cases of symptoms of disorders of the musculoskeletal system than those with a good level of practice $(P=0.000)$. This finding is corroborated by the findings of authors who both reported that, when the necessary ergonomic principles are not applied, there is usually a resultant occurrence of work-related disorders of the musculoskeletal system. ${ }^{[17,19]}$

\section{Conclusion}

In this study, it was found that majority of the respondents had good knowledge and attitude toward prevention of musculoskeletal system disorders at work. The practice of ergonomic principles necessary for the prevention of these disorders of the musculoskeletal system was, however, not satisfactory. It is recommended that health personnel should be re-oriented to be more involved in the actual application of ergonomics while working no matter the compulsion or desire to get work done. Strict adherence to leave periods and properly utilizing such periods to rest the musculoskeletal system of the body were also recommended.

\section{References}

1. Leggat PA, Kedjarune U, Smith DR. Occupational health problems in modern dentistry: A review. Ind Health 2007;45:611-21. [PubMed]

2. Parsa-Parsi RW. The revised declaration of Geneva: A modern-day physician's pledge. JAMA 2017;318:1971-2. [Crossref] [PubMed]

3. Shipra N, Rohit N, Aggarwal NG. Ergonomic principles to prevent musculoskeletal disorders in dental professionals. Int J Dent Health Concerns 2015;1:1-5. [Crossref]

4. Mehrdad R, Dennerlein JT, Morshedizadeh M. Musculoskeletal disorders and ergonomic hazards among Iranian physicians. Arch Iran Med 2012;15:370-4. [Crossref] [PubMed]

5. Ayanniyi O, Nudamajo OS, Mbada CE. Pattern of work-related musculoskeletal disorders among Nigerian hospital workers. J Environ Occup Sci 2016;5:18-24. [Crossref]

6. Bassey DE, Eduwem DU, Inah GU, Udoaka A, Akintomide AO. Work related musculoskeletal disorder amongst sonologists in Nigeria. IOSR J Dent Med Sci 2013;10:68-71.

7. Sokunbi OG, Jaiyeola AO, Maduagwu MS, Ibrahim M. Patterns of occurrence of work-related musculoskeletal disorders and its correlation with ergonomic hazards among health care professionals. Niger J Exp Clin Biosci 2015;3:18-23. [Crossref]

8. Yasobant S, Rajkumar P. Work-related musculoskeletal disorders among health care professionals: A cross-sectional assessment of risk factors in a tertiary hospital, India. Indian J Occup Environ Med 2014;18:75-81. [Crossref]

9. Yasobant S, Rajkumar P. Health of the healthcare professionals: A risk assessment study on workrelated musculoskeletal disorders in a tertiary hospital, Chennai, India. Int J Med Public Health 2015;5:189-95. [Crossref]

10. Syed AA, RavishankarTL, Amit T, Vaibhav T, NidaH, Ketan S, et al. Ergonomic considerations and prevalence of musculoskeletal disorders among dental practitioners of Uttar Pradesh, India. Int J Recent Sci Res 2017;8:17725-8. [Crossref]

11. Balaji H, Dhanraj D. Prevalence of musculoskeletal disorders of neck, shoulder and lower back region in dental professionals. Int J Sci Res 2017;6:1951-5.

12. Wadhawan R, Luthra K, Sidhu JK, Solanki G. Comforting the dental surgeon a review on ergonomics. Int J Odontol Sci 2015;1:1-9.

13. Roma Y,Radhika R, Abhishek Y, Meetika P, Savita S. Ergonomics for pain free dental practice a review. Int J Inf Res Rev 2016;3:2562.

14. Nkhata LA, Esterhuizen TM, Siziya S, Phiri PD, Munalula-Nkandu E, Shula $H$. The prevalence and perceived contributing factors for work-related musculoskeletal disorders among nurses at the university teaching hospital in Lusaka, Zambia. Sci J Public Health 2015;3:508-13. [Crossref]

15. Siddiqui TM, Wali A, Khan $\mathrm{OH}$, Khan M, Zafar F. Assessment of knowledge, practice, and work environment related to ergonomics among dental students and dental practitioners. Int J Contemp Dent Med Rev 2016;2016:40316. [Crossref]

16. Seyed AZ, Mohammad RM, Somayeh FD, Majid HM, Hossein S, Mehdi A. Relationship between knowledge of ergonomics and workplace conditions with musculoskeletal disorders among nurses: A questionnaire survey. World Appl Sci J 2013;24:227-33. [Crossref]

17. Ashu MA, Kamo H. Work-related musculoskeletal disorders amongst oral health workers in Cameroon. Oral Health Dent Manag 2016;15:1-6.

18. Kalghatgi S, Prasad KV, Chhabra KG, Deolia S, Chhabra C. Insights into ergonomics among dental professionals of a dental institute and private practitioners in Hubli-Dharwad twin cities, India. Saf Health Work2014;5:181-5. [Crossref] [PubMed]

19. Bushra R, Ayesha A, Afsheen A, Anum T. Ergonomic hazards to dental surgeons: A cross-sectional study. Pak Oral Dent J 2016;36:168-71.

20. Karibasappa GN, Sujatha A, RajeshwariK. Dentists' knowledge, attitude and behavior towards the dental ergonomics. IOSR J Dent Med Sci 2014;13:86-9.

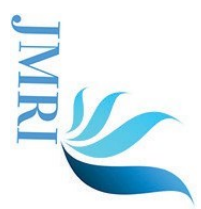




\section{Ephraim-Emmanuel, et al.: KAP preventing Work-related musculoskeletal disorders}

21. Federal Ministry of Health. List of all Federal Teaching Hospitals. Nigeria: Federal Ministry of Health; 2014.

22. Google. "Location of University of Port Harcourt Teaching Hospital" (Map). Google Maps. Nigeria: Google; 2014.

23. Lwanga SK, Lemeshow S. Sample Size Determination in Health Studies: A Practical Manual. Geneva: World Health Organization; 1991. Available from: http://www.who.int/iris/handle/10665/40062. [Last accessed on $2018 \mathrm{Jul}$ 06].

24. Osazuwa-Peters N, Azodo CC, Obuekwe ON. Occupational health issues of oral health care workers in Edo state, Nigeria. Int Dent J 2012;62:117-21. [Crossref]

25. Abi AL. Musculoskeletal disorders among Lebanese dentists trend evolution. J Oral Med Toxicol 2016;1:1-5. [View Article]

26. Hassan EE, Elkhateeb AS, Ewis AA, Ali AN. Musculoskeletal disorders among dentists and physicians at minia university hospitals; A comparative study. Egypt J Occup Med 2017;41:55-70. [Crossref]

27. Kaewboonchoo O, Yamamoto H, Miyai N, Mirbod SM, Morioka I, Miyashita K. The standardized Nordic questionnaire applied to workers exposed to-
Hand arm vibration. J Occup Health 1998;40:21822. [Crossref]

28. Launiala A. How much can a KAP survey tell us about people's knowledge, attitudes and practices? Some observations from medical anthropology research on malaria in pregnancy in Malawi. Anthropol Matters J 2009;11:1-13. [View Article]

29. World Health Organization. Advocacy, Communication and Social Mobilization for TB Control: A Guide to Developing Knowledge, Attitude and Practice Surveys. Geneva: World Health Organization; 2009.

30. Fujishiro K, Weaver JL, Heaney CA, Hamrick CA, Marras WS. The effect of ergonomic interventions in healthcare facilities on musculoskeletal disorders. Am J Ind Med 2005;48:338-47. [Crossref] [PubMed]

31. RajaK, Auxilia HT. Occupational hazards in dentistry and its control measures a review. World J Pharm Pharm Sci 2014;3:397-415.

32. Valachi B, Valachi K. Preventing musculoskeletal disorders in clinical dentistry: Strategies to address the mechanisms leading to musculoskeletal disorders. J Am Dent Assoc 2003;134:1604-12. [Crossref] [PubMed] 